Article in press

\title{
Lean Business Models Change Process in Digital Entrepreneurship
}

Please cite as:

Balocco, R., Cavallo, A., Ghezzi, A., Barbegal-Mirabent, J. (2019). Lean Business Models Change Process in Digital Entrepreneurship. Business Process Management Journal, 1-24.

DOI:10.1108/BPMJ-07-2018-0194

\section{Raffaello Balocco, Angelo Cavallo*, Antonio Ghezzi, Jasmina Barbegal-Mirabent}

\section{Raffaello Balocco}

Politecnico di Milano, Department of Management, Economics and Industrial Engineering, Via Lambruschini, 4/B, 20156 Milano, Italy.

E-mail: raffaello.balocco@polimi.it.

\section{Angelo Cavallo*}

Politecnico di Milano, Department of Management, Economics and Industrial Engineering, Via Lambruschini, 4/B, 20156 Milano, Italy.

E-mail: angelo.cavallo@polimi.it.

\section{Antonio Ghezzi}

Politecnico di Milano, Department of Management, Economics and Industrial Engineering, Via Lambruschini, 4/B, 20156 Milano, Italy.

E-mail: antonio1.ghezzi@polimi.it

Jasmina Berbegal-Mirabent

Department of Economy and Business Organization, Universitat Internacional de Catalunya, Barcelona, Spain

Email: jberbegal@uic.es.

\footnotetext{
* Corresponding author
} 


\title{
Lean Business Models Change Process in Digital Entrepreneurship
}

\author{
Structured Abstract
}

Purpose: Business Model Change (BMC) is a process new ventures are frequently involved in, especially in dynamic environments like the Digital Industry: copying with it is a key issue for entrepreneurs attempting to shorten the transition between current and new business models (BMs) and avoid losses in terms of revenue, image and customer retention, while acquiring experience and validated learning in the process. Our study aims at proposing a lean framework to support digital new ventures in the Business Model Change (BMC) process.

Design/methodology/approach: The study builds its contribution on two pillars: a review on BM and the Lean Thinking theories; and a multiple case study on three digital new ventures which underwent BMC.

Findings: The study shows how BMC in a Digital context can beneficially follow lean principles, and how these principles can be integrated in an original Lean framework to experiment on, validate and subsequently change a BM.

Originality/value: We provide the SMED4BMC framework that extends and complements Lean Startup Approaches to further relate Lean Thinking and Business Model Change, thus operationalizing the process of BM experimenting and validation that enables change.

Keywords: Business Model; Lean Startup; Lean Manufacturing; Digital Entrepreneurship; Business Model Change; Business Model Validation; Business Model Experimenting

Article Classification: Research paper

\section{Introduction}

This study explores how new ventures are processing Business Model Change (BMC) and the role played by Lean Startup Approaches (LSAs) in BMC process. New ventures are known as small companies looking for a proven business model, while being continuously involved in a change and adaptation process (Lichtenstein, and Brush, 2001; Andries and Debackere, 2006). This is especially true when considering digital new ventures operating in dynamic and uncertain environment (Courtney, et al., 1997; Sirmon et al., 2007; Ghezzi and Cavallo, 2018). Such change aims at acquiring experience and learning concerning the new venture's ability to create and to possibly capture value, that is, to set up a value architecture (Timmers, 1998; Rappa, 2001) also known as Business Model (Teece, 2010; Zott et al., 2011; Saebi, Lien and Foss, 2017).

A recent and extensive literature has been discussing how companies change and innovate their business 
model (e.g. Spieth et al., 2014; Foss and Saebi, 2017; Saebi, Lien and Foss, 2017; Ghezzi and Cavallo, 2018). A wide school of researchers are focusing their research effort on the degree of novelty introduced by BM changes (for a recent systematic review on Business Model Innovation, see Foss and Saebi, 2017), leaving less attention on how changes in BM are processed. Performing changes in a BM may likely lead to innovation, though it is neither warranted nor revealed ex-ante (Saebi, Lien and Foss, 2017). In this study, we will focus on BMC process, defined as alteration of meta-routine of value creation and appropriation (Zott and Amit, 2007; Chesbrough, 2007; Zott, Amit, and Massa, 2011; Osiyevskyy and Dewald, 2015) - while assessing the degree of novelty reached by such changes in business model lies outside of the scope of our research.

The debate on BMC has been enriched by Osiyevskyy and Dewald (2015). They conceptualize two distinct forms of BMC: (i) explorative (radical) - i.e. rethinking the way value is created, distributed and captured; and (ii) exploitative (incremental) business model change - i.e. incrementally strengthening of the existing business model.

The research on BMC has been largely focused on well-established organizations, as it referred to incumbent companies and their BMC process (Achtenhagen et al., 2013; Bohnsack et al., 2014). However, in a constantly and fast-changing competitive scenario characterized by Schumpeterian waves of creative destruction (Scherer, 1986), new ventures in entrepreneurial ecosystem (Cavallo et al., 2018a) share with wellestablished companies the strategic challenge of continuously adapt and change. Indeed, even if these new ventures are born with a substantially original and potentially disruptive business model, being disrupted while attempting to disrupt the industry is not an unlikely event. This suggests that the threat of being disrupted by newcomers may impact all types of companies (Christensen et al., 2006), including young and small organizations like new ventures. For new ventures, an ongoing experimenting, adaptation and change is essential in order to gain a sustainable competitive advantage in the current market scenario (NichollsNixon et al., 2000; Gersick, 1994). However, research on new ventures' BMC and how new ventures may process their BMC is still underdeveloped (Kesting and Günzel-Jensen, 2015), though theoretical and practical implications concerning this proceeding could be extremely important for entrepreneurs.

To deal with such need, a set of pragmatic approaches that go under the name of "Lean Startup Approaches" (LSAs) (Ghezzi and Cavallo, 2018) emerged, which aim at supporting entrepreneurs in the process of validating their business model's assumptions through market tests and early customer feedbacks (Ries, 2011; Blank, 2013). The LSAs find their origin in the broader - and not certainly new - "Lean Thinking" and its first and notorious application in the manufacturing sector. Ries (2011), Blank (2013), followed by other practitioners in the entrepreneurial community, had the merit to introduce the Lean Thinking in the entrepreneurial strategy field. Their practical approaches reached a great audience, and it is a fact that entrepreneurs widely recognize to be inspired by LSAs in their early stages of strategy development 
(Frederiksen and Brem, 2017; Yang et al., 2018). Although a common denominator between lean thinking and lean startup is the use of creativity and experimentation to pursue innovation (Baldassarre et al., 2017) while cutting waste (Ghezzi and Cavallo, 2018), the relation between Lean Thinking and LSAs to support BMC has not been fully explored in the literature as of yet. The few studies analyzing LSAs often dismiss such relation as an element to be taken for granted; however, we argue that much is unsaid concerning the extent to which LSAs can leverage Lean Thinking to enact BMC.

This study hence explores how new ventures, inspired by LSAs and Lean Thinking as a whole, are processing BMC. Ultimately, this study provides an integrated framework that extends and complements LSAs and is expected to help entrepreneurs while facing a BMC process.

To this aim, this study leverages a multiple case study (Yin, 2013). We selected a homogenous sample including three new ventures operating in the digital industry in their early stage of development that already experienced changes in their business model, and we analyzed how such process disentangled, to eventually formulate our original framework.

The remainder of the study consists of five sections. Following the introduction, in Section 2 we present the theoretical background as basis of our investigation. In Section 3, we describe the research design, method and results. Sections 4 and 5 respectively discuss the results and draw conclusions focusing on research value and managerial implications. Finally, in section 7, limitation and future research direction are provided.

\section{Literature review}

In the first part of this literature review we will present a short overview on the Business Model (BM) theory. This will be followed by a review of the Lean Thinking, as a powerful theory deeply influencing the business processes across many industries.

\subsection{Business Model Theory}

$\mathrm{BM}$ is the integration point among different theories and is considered as the new comprehensive unit of analysis (Amit and Zott, 2001; Kurti and Haftor, 2014) revolving around the notion of value. BM has the ability to formalize strategic assumptions and 'tell a story' which makes everyone in the organization aligned on common values and goals (Magretta, 2002). The resulting collective knowledge increases chances of survival of a firm (Greve, 1998), thus making the BM a source of competitive advantage (Zott et al., 2011; Afuah and Tucci, 2001; Doz and Kosonen, 2010; McGrath, 2010). Scholars find agreement while defining BM as the process through which an organization creates, delivers, and captures value (economic, social, or in other forms) in relationship with a network of exchange partners (Osterwalder et al., 2005; Teece, 2010; Zott et al., 2011; Afuah and Tucci, 2001; Kulins, et al., 2016; Saebi, Lien and Foss, 2017). The literature also recognized the dynamic nature of BM. BMs may evolve, change and be source or vehicle of innovation (Mitchell and 
Coles, 2003; Massa and Tucci, 2013). Innovation through Business Model - or simply Business Model Innovation (BMI) - attracted an enormous attention from both practitioners and leading scholars (Zott et al., 2011; Saebi, Lien and Foss, 2017). BM and Innovation are two concepts historically linked in the literature of technology management and entrepreneurship (Massa and Tucci, 2013). BM can be considered as a device to manipulate that mediated between technology and economic value creation (Chesbrough and Rosenbloom, 2002) i.e. a vehicle of innovation. Therefore, the Business Model can also be itself a source of innovation, the determinant of superior performance even in mature industries (Zott and Amit, 2007), or as Christensen (Christensen, 1997) claims a "source of disruption".

Mitchell and Coles (Mitchell and Coles, 2004) explain the business model innovation process by means of different degrees of change. Starting from a very simple definition of BM - "a business model comprises the combined elements of 'who', 'what', 'when', 'why', 'where', 'how' and 'how much' involved in providing customers and end users with products and services" - Mitchell and Coles (2004) argue that BMI process can start with changing a single business model element - business model improvement - that may become "BM replacement" if it entails improving at least four of these business model elements versus the competition. And finally, as last step of a continuous changing phenomenon, a business model replacement providing services or product not previously available can be considered "business model innovation". Since Mitchel and Coles's seminal work, the literature on BMI has been growing considerably. Saebi, Lien and Foss (2017), starting from Mitchel and Coles work provide a review of the extensive literature on BMI and define BMI as “designed, novel, nontrivial changes to the key elements of a firm's business model and/or the architecture linking these elements". The Business Model Innovation process is first of all a "change phenomenon" which, if characterized by some degrees of novelty or uniqueness comparing to already existing solution in the market, can lead to a business innovation process (Massa and Tucci, 2013). However, there has been less attention on how changes in BM are processed. Performing changes in BM might likely lead to innovation, though it is neither warranted nor revealed ex-ante (Saebi, Lien and Foss, 2017). Business Model Change (BMC) process is an alteration of meta-routine of value creation and appropriation (Zott and Amit, 2007; Chesbrough, 2007; Zott, Amit, and Massa, 2011; Osiyevskyy and Dewald, 2015). The debate on BMC has been enriched by Osiyevskyy and Dewald (2015). They conceptualize two distinct form of BMC: explorative (radical) - i.e. rethinking the way value is created and distributed, and exploitative (incremental) business model change - i.e. incrementally strengthening of the existing business model. Companies may adopt a pure explorative business model change strategy or pure exploiting business model change strategy as well as simultaneously conducting both strategies (Charitou and Markides, 2003; Osiyevskyy and Dewald; 2015; Choudhary et al., 2018). Successful companies consider BM change, an imperative to exploit new opportunities (Achtenhagen et al., 2013) and it is a continuous experimentation and trial and error learning process (Morris et al., 2005). 
The literature shows notable contributions and evidence on successful example of business model change and innovation process mainly regarding large organizations (Schaltegger et al., 2012; Chesbrough, 2007; Sosna et al., 2010; Amit and Zott, 2012; Johnson et al., 2008; Knab and Rohrbeck, 2014), though, BMC can regard big as well as small organizations (Klewitz and Hansen, 2014) and other entities within wider entrepreneurial ecosystem (Stam, 2015; Cavallo et al., 2018 a; Cavallo et al., 2018 b). Hence, scholars seldom focus on new venture where the need of a continuous business model change and innovation is even more perceived compared to established firms. For new ventures change becomes a permanent state, a finetuning process, and firm sustainability depends on the capacity of anticipating and responding to changes (Demil and Lecocq, 2010). Demil and Lecocq (2010) term dynamic consistency the firms' ability to keep high level of performance while building a new business model. Experimentation often requires a long period of co-existence between current and new model and organizational problems can arise (Chesbrough, 2010; Scuotto et al., 2017). Indeed, a multiple business model configuration has several risks such as cannibalization and compromising quality and network (Doz and Kosonen 2010).

As a whole, we conclude that the existing literature underscores the need to provide tools and practices that help entrepreneurs cope with the business model change process.

\subsection{Lean Thinking: from Manufacturing to Entrepreneurial Strategy}

Lean thinking revolves around a core idea: maximize customer value while minimizing waste. This implies that Lean calls for creating more value for customers with fewer resources. The most central aspect of this methodology is its focus on deep understanding of the user and the ability to rapidly respond to their expectations (Bicen and Johnson 2015), sometimes even before this demand is articulated. Accordingly, a lean organization should understand where the customer value is and identify the key processes to continuously increase the customer value.

The Lean Thinking originated after the end of the Second World War, as customer's needs and expectations evolved from being largely homogeneous to significantly heterogeneous, and it became apparent that the American industrial paradigm of mass production was not able to fulfill them anymore. In the 1950s, Eiji Toyota and Taiichi Ohno started a process of adaptation of the automobile company Toyota and its production systems to consumers, in order to create and sustain competitive advantage (Costa et al., 2013). This allowed the Japanese firm to gain a global production leadership against the USA. Five simple principles made it possible: 1) Create value for the customer; 2) Identify the value stream; 3) Create flow; 4) Produce only what is pulled by the customer; 5) Pursue the perfection (Womack and Jones, 1996; Hines et al., 2004). These principles became the foundation of the Lean Thinking, which represents a widespread manufacturing and managerial philosophy nowadays. Figure 1 illustrates these principles based on Womack and Jones (1996): 
Figure 1. Lean Manufacturing Principles (Womack and Jones, 1996)

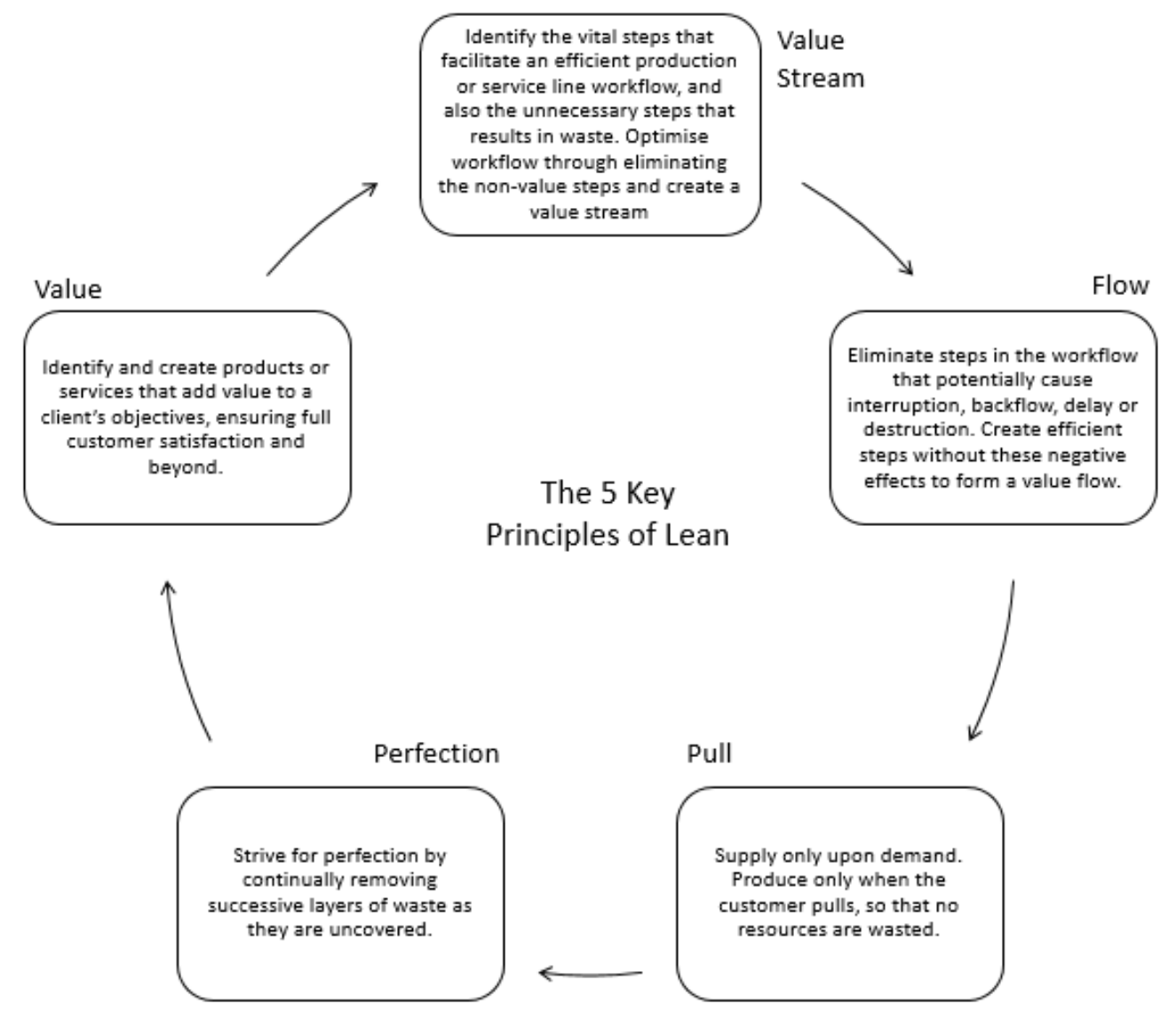

Since popular approaches are often subject to misconceptions, for decades it was believed that lean thinking was suitable only in the manufacturing domain. However, recent attempts emerged that apply Lean thinking in varied businesses and processes. Lean is a way of thinking and acting for an entire organization, and not merely a tactic or a cost reduction program.

Indeed, Lean thinking and its principles gradually extended their validity and impact in several other fields, and at different granularity and level of investigation. For instance, Hines et al. (204), investigate the organizational and individual elements of Lean; in "Making R\&D lean", Reinertsen and Shaeffer (2005) show how a careful implementation of this philosophy can enhance R\&D results and psychological motivation in the exploration activity at a functional level; while at a more aggregate level, Dezi et al. (2018) describe a model of lean smart city. Similarly, Blank (2006) and Ries (2011) adapted the principles to the entrepreneurial strategy area by elaborating the "Lean Startup Approaches" (LSAs), intended as a combination of the Lean Startup and Customer Development (Ghezzi and Cavallo, 2018). Table 1 illustrates the touchpoints between Lean Manufacturing and LSA: 
Table 1. From Lean Manufacturing to Lean Startup: touchpoints

\begin{tabular}{cc}
\hline Lean Manufacturing & Lean Startup Approach \\
\hline $\begin{array}{c}\text { Create value for the customer } \\
\text { Identify the value stream } \\
\text { Create flow }\end{array}$ & Minimum Viable Product (MVP) \\
Lean Canvas \\
customer \\
Pursue the perfection
\end{tabular}

LSAs are essentially based on the application of the scientific method to entrepreneurial endeavors. To foster a scientific approach to new ventures' launch, the Minimum Viable Product (MVP) is a central concept: MVP emphasizes the need to focus on creating only what the customer really values and it can even be pursued with a front-end product backed by humans instead that automated ("Wizard of Oz testing") (Kefalidou and Sharples, 2016). The MVP artifact, which enables rapid prototyping to get feedback from real users, is the cheapest way for verifying hypotheses concerning how new ventures' business models should be designed and validated. Through this process, companies are able to get consumer insights and unattended needs, which might eventually lead to new breakthrough insights (Bicen and Johnson 2015).

With the aim to extend LSAs, Maurya (2012) proposed the Lean Canvas tool to picture the main business model elements calling for experimenting and validation. The Lean Canvas is used to identify the way of delivering value to the customer by documenting assumptions and measuring and communicating their progress/changes over time (Maurya, 2012). Once the value stream is consolidated, the continuous deployment cycle is the way for minimizing every type of lead time by immediately deploying new code, thus creating flow. The voice of the customers pulls what an organization produces and it is heard by asking them directly, getting out of the building. Along all the organizational processes, continuous testing (measure), learning and improvement (build) are key for pursuing perfection (Maurya, 2012).

LSAs gained momentum in the entrepreneurial community around the world (Yang et al., 2018) because of the recognition that limited resources characterize startups, and wastes in time and money can be fatal (Ries, 2011). Only a very small percentage (2-10\% depending on the industry) of startups have success (Blank, 2006; Mullins and Komisar, 2009). A startup differs from an established company since it innovates without a deep knowledge of its customer base, moving from a vision that has still no audience (Ries, 2011). According to Bicen and Johnson (2015) lean firms act like bricoleurs, as they should rapidly combine the available resources and propose new solutions in an experimental way. In this respect, startups' success depends heavily on their ntrepreneurial strategy; in other words, on "how new ventures are run" (Blank, 2006; Ries, 
2011; Maurya, 2012). The typical startups' mistake is to develop a product that no one needs. This is what Reis call "successfully executing a bad plan". Thus, LSAs - as application of the lean Thinking - may result of high potentials since it supports the process of discovering what people really want by launching a product much more quickly and with limited expenses. Summarizing, LSAs favors:

1. Experimentation over overelaborated planning;

2. Customer feedback over intuition;

3. Iterative design over traditional "big design up front" development.

LSAs are exemplary cases of how the entrepreneurial strategy field can benefit from applications of Lean Thinking. Specifically, Ries (2011) and Blank (2013) argue that LSAs really fit with software and digital new ventures, thus revealing the role LSAs in digital entrepreneurship; this claim is corroborated by the empirical findings from Ghezzi (2018), who employs a mixed-method research on a large sample of 227 digital startups to show how LSAs are extensively adopted, jointly with other entrepreneurial and strategic tools - e.g. the traditional Business Plan - to experiment on and validate original BMs. Despite the fact that some works examining the adoption of lean thinking practices among entrepreneurs and small businesses, literature is still limited. In this respect, and based on the LSAs, Girgenti et al. (2016) propose a framework to systemically build a customer development model aimed at verifying the agreement between what is offered and what customer needs. The empirical application considers the automobile sector. Also rooted in Blank (2013), Brad et al. (2016) and Weissbrod and Bocken (2017) develop a method to evaluate and pursue disruptive and radical innovations, respectively, while Tanev et al. (2015) address the concept of lean global start-ups to unfold the problems that new technology start-ups face when dealing separately with business development, innovation and early internationalization. Other recent trends include those works that focus on specific industries. For instance, Bajwa et al. (2017) investigate the major types of pivots of software startups during the initial stages, Still (2017) applies this paradigm to the context of research at universities and other research-intensive organizations. Finally, there is a last group of studies that combine lean with agile, resilient and green principles into an integrated business model framework as a way to develop sustainable competitive advantage (Wiese et al., 2015; Cabrita et al. 2016; Caldera, Descha and Dawes, 2017).

\section{Research Design}

This study will assess a possible way to process BMC for digital new ventures. This study leverages on a multiple longitudinal case study (Yin, 2013) on three companies operating in the same (digital) industry, which made it possible to mend the limitations of the single case studies - these limitations being mainly related to the poor ability to generalize results obtained from a single case (Meredith, 1998; McGrath, 2010). 
To ensure anonymity, we will refer to the three firms we analyzed with the following pseudonyms: Crowd; Matching; Navigate. Moreover, we chose a homogenous sample of a single industry (digital), eliminating industry effects and increasing internal validity. Still, the limited number of Digital Startups included in the sample allowed to maintain the positive properties of the single case study methodology, related to the provisioning of an extensive qualitative description and analysis of BMC in the new ventures' early stages of development, with the needed depth and insight, difficult to replicate when considering a wider sample (Handfield and Melnyk, 1998). Within all three cases, our unit of analysis was the early stage BMC process the Digital Startup undertook, with its steps as possible sub-units of analysis.

\subsection{Sample selection and Data Gathering process.}

In this section, we will present the full process that lead us to identify the three cases under investigation and relative data gathering process.

The process started with a preliminary survey on $6,018^{1}$ innovative new ventures ${ }^{2}$ registered in the Italian Chamber of Commerce Firms Register (Special Section). Those innovative new ventures are mainly belonging to the hi-tech sector (Calcagnini et al. 2016; Colombelli 2016; Cavallo et al., 2018b), and aged between 1 to 5 years, thus can be considered as young firms in their early stages of development following Puri and Zarutskie (2012). Since each firm may access several benefits through the enrolment in the Register, this is a valuable source of information for examining new ventures (Cavallo et al., 2018). A two-wave survey was carried out to increase the respondent rate. As a result, we received 732 complete responses; 242 responses were discarded since the new ventures did not operate in the digital sector (but rather in other hi-tech industries such as life-science and clean-tech). Finally, the 32 new ventures were selected for further investigation, since they had declared simultaneously: 1) to have adopted major/minor changes to the Business Model; 2) to know the LSAs; 3) to be available for direct interviews. Some useful preliminary information about the 32 companies was collected through secondary sources (in order to avoid loss of time during the subsequent interview). Thus, from their company website we gained a preliminary understanding of their mission, targets and values. More importantly, financial data were collected from AIDA database (by Bureau Van Dijk Electronic Publishing) and The Italian Firms Register of Chamber of Commerce, enabling us to identify those new ventures that 1 year after adopting changes in their BM showed a substantial increase in revenues.

After gaining a preliminary knowledge of our sample, we conducted 32 interviews with at least one founder for each startup (in 15 cases, two founders participated in the interview while in 3 cases three founders had

\footnotetext{
${ }^{1}$ Updated to $18 / 07 / 2016$

${ }^{2}$ Innovative new venture has been defined by the Decree Law 221/2012 as 'a firm, not listed and subject to Italian tax law, which has a turnover of less than 5 million euros, has been operational for more than 48 months, is owned directly for at least $51 \%$ by physical subjects, and, more importantly, has the social aim of developing innovative products or services, with a high technological content' (Colombelli, 2016, p.386).
} 
participated in the interviews). In the end, three cases were selected based on the following criteria: 1) the new ventures undertook changes in the business model in a deeply different way, thus increasing results generalizability; 2 ) the new venture's BMC process had a significant impact on its performance, as witnessed by a substantial increase of revenues one year after the $\mathrm{BMC}^{3}$.

In the timeframe February-July, 2017, 9 qualitative interviews (lasting one hour and thirty minutes on average) on the three cases were performed, involving the key strategic decision makers in the new ventures (i.e. founders). Interviews were all conducted at the companies' headquarters. The case studies' scheme of analysis focused on exploring the entrepreneurs' strategic choices during the BMC process, as well as the explicit or implicit use of lean principles. As result, the interviews included questions on the role of the Lean Startup Approaches ("How did you know about Lean Startup and/or Customer Development? Did you get inspired by LSAs? Does your organization practically adopt this approach? If yes, can you describe in which occasion has been adopted? and How?) and questions aimed at explore on the breadth and depth of changes in the BM (e.g. "What did you change in your Business Model? and How?"). The reference framework on BM that we have used though the interviews is the Business Model Canvas. The tool has been developed by Osterwalder and Pigneur (2010) and includes only internal factors (Osterwalder, 2004) distributed among 4 areas of value (proposition, customer interface, internal infrastructure and value formula) and 9 building blocks enabling a one-page representation of a company (Osterwalder and Pigneur, 2010). This representation has been chosen by the authors as it is the most used by practitioners while building a strategy plan (Chesbrough, 2010; Guemes-Castorena and Toro, 2015; Rytkönen and Nenonen, 2014). Often, academics' and practitioners' worlds show a certain distance, speaking different languages. As this study aims to reduce the barrier among academic and practitioner, selecting a tool that is increasingly used by entrepreneurs enables a more fruitful communication, especially during interviews.

Since the validity and reliability of case studies rest heavily on the correctness of the information provided by the interviewees and can be assured by using multiple sources or "looking at data in multiple ways" (Eisenhardt, 1989; Yin, 2003), in addition to interviews, other multiple sources of evidences or research methods have been employed, including internal documents, websites and other secondary sources (external databases, newsletters, whitepapers). This combination of sources allowed obtaining "data triangulation", essential for assuring rigorous results in qualitative research (Bonoma, 1985). Table 2 summarizes all data sources considered for this study.

\footnotetext{
${ }^{3}$ This can be considered as proxy of a successful implementation of BMC .
} 
Data Type

Survey

Preliminary interviews

Interviews

External Documents and sources

Archival records
Quantity

2

32

9 (3 for each case study)

32 (6 - Internet pages; 22 - Newspaper articles; 2

- Whitepapers; 2 - Databases)

69 (3 - Business Plan; 64 - Informal E-mails; 2 Meeting Minutes)

\subsection{Data Analysis}

The empirical material was codified through textual analysis (while a software was used as archive). Both invivo and constructed $\operatorname{codes}^{4}$ (Glaser and Strauss, 1967) led to identify the first-order (or "core") categories. Based on Gioia et al. $(2010 ; 2013)$, data were structured by ordering data from specific, "core" categories used by informants to more general, researcher-induced second-order themes and above all overarching dimensions (Yin, 1984). This process is a key component to ensure rigor in qualitative research (Pratt, 2008; Tracy, 2010; Gioia, et al. 2013). The research 'core categories' were based - though not restricted to - the theoretical background and the original conceptual model by applying the 'open coding' interview transcriptions (Corbin and Strauss, 1990). The second order themes, due to their direct relevance while addressing the study's research questions, represent a synthesis of the key themes emerged from the multiple case study. This made it possible to verify the correspondence between the themes proposed in the model and additional themes mentioned by the case study participants. Therefore, those earlier themes were cross-referenced once again with theory and other data sources in order to foster the reliability and internal validity of the case study material (Denzin, 1978).

\section{Results}

\footnotetext{
${ }^{4}$ The complete list of codes employed is available upon request.
} 
The multiple case study includes on three cases of digital new ventures which experienced a business model change process in an original fashion.

\subsection{Crowd}

Crowd is a new venture founded in 2011. The company provides an innovative crowdsourcing-based service for store checks and mystery shopping to medium and large firms that need to control their current distribution channels. The new tool is a revolution in this classically slow and expensive industry. Everyone living in a given geographical area can become a precious resource downloading the application, thus becoming part of the "crowd". From the other side, companies access to the app and create tasks while paying to receive reviews on bars, pubs, restaurants and other commercial activities (job self-creation function). Crowd receives surveys, information and pictures from the crowd and then validates, screens, aggregates and analyses them for the final presentation to its business customer.

Crowd had a very close relationship with customers. The personal contact of the startup's management with its customers, revealed that some service features needed to be changed. Indeed, the customizable job selfcreation function, at first perceived as a value, was of difficult usage given the too big variety of tasks specifications. Furthermore, quantitative metrics revealed a very low profitability suggesting a change in the revenue model.

As a result of this feedback cycle, a new business model was envisioned and built. New key resources, key activities, value proposition and revenue stream were needed for creating a novel system with a higher product-market fit. The main difference was the creation of a specialized sales function taking care of formalizing customers "jobs" through a fully-managed process that substituted the previous "self-service".

Between October 2012 and March 2013, Crowd worked on a process of renewal. With a clear idea about the future desired state, the first action was in the direction of acquiring new key resource. Three months of market search allowed to find the right people and to create a sales force function. Later on, clients started to experiment the new value proposed. The fully managed "job" creation process was simulated through a Wizard of $\mathrm{Oz}$ testing version: indeed, the personal sellers were using the self- service job creation function substituting the customer, but a new centralized system did not yet exist and the IT tools were unchanged. Once testing was complete, the new functionalities were automated and the last step was a change in the revenue model by creating a new system for pricing a job based on location, requirements and other parameters. Eventually, Crowd started having profits.

\subsection{Matching}

Matching is a digital new venture founded in 2011. The founders recognized a need for a platform able to match offer (businesses) and demand (users) for services such as cleanings, house maintenance and 
reparations. When an individual requires a service through the platform, businesses view the request and can send their quotes. Users then choose the service provider and Matching receives a commission on each transaction in the range $5-7 \%$ (pay per transaction model).

Positive signals came from the analytics confirming that clients appreciated the value proposition, the distribution channels were well selected and that Matching had the right key resources for reaching a product-market fit. However, there was one indicator that scored under the expectations: the revenues.

Furthermore, by leveraging on a continuous customers' feedback process, the founders realized that there was a related need of changes also in the key activities, customer relationship and customer segmentation. In the pay-per-transaction model, debt collection was a key activity, given the intermediary role played by Matching. As a result, Matching had to cope with high operation costs affecting revenues and scalability. Therefore, this model could affect also the relationship with customers. Lastly, business clients were not differentiated and they all needed to pay Matching in the same modality.

In November 2013, Matching decided to modify its business model. Founders designed a new cost-per-lead model. Every time a user publishes a demand, businesses can decide to buy the request for being able to send their quote. At this point contacts are exchanged and become direct without need of other activities by Matching (reaching the elimination of debit collection and protection of user contacts).

In a second moment, the businesses using the platform had been differentiated in professionals, small and medium enterprises and key accounts. This new segmentation enabled the creation of tailored offers inside the cost-per-lead structure.

Even the relationship with customers changed and benefited from the introduction of the new cost-per-lead revenue model that transformed Matching from a "debt collector" to a friendly brokering service.

\subsection{Navigate}

Navigate is a digital venture founded in 2013 after a period of research conducted by three university students. They envisioned an innovative system enabling localization and navigation inside buildings where GPS technology finds its limits. Navigate target customers are public institutions, museums, shopping malls, exhibitions and airports having their own application (APP). Navigate sells a license for a standard software development kit (SDK) that clients could customize and implement in their own pre-existing mobile software for offering a best experience to users. The new technology is based on the installation of beacons in the building where the navigation needs to take place. Beacons send signals able to identify the position of users nearby thus enabling an off-line navigation.

Despite the positive economic results, the founders decided not to focus only on exploiting the current opportunity but to explore new ones, such as: advertisement and data analysis. 
The old model was not eliminated but constituted the basis for a change process that shifted the focus from software to services provisioning.

As a first step, founders had a clear idea and formalized the future business model.

Secondly, the new business needed key resources as the creation of a unique APP and the acquisition of new specific knowledge in data analysis and digital marketing. Furthermore, since proximity market works in a less invasive way by guiding customers to a shop while he is still at a certain distance, new contracts with building providers have been signed for developing a beacon hive in strategic positions. New partnerships with beacon producers and companies offering services complementary to Navigate have been created, driving cost down and demand up. All the previous efforts enable the company to enlarge the customer base to businesses that do not have their own APP (hereinafter referred to as "new customers") through the new unique APP encompassing also advertising and more advanced marketing activities. The APP was introduced first only in the Google Play store and with limited functionalities for testing reasons. Old and new customers can benefit from analysis of data collected such as time spent in front of a showcase, in a corridor, number of visits and so on. This service is paid on top of the pre-existing periodic licensing and expanded the revenue model.

Revenues from advertisement are hence shared among building providers and Navigate.

\section{Discussion}

\subsection{The role of Lean Startup Approaches in Business Model Change Process}

The interviewee of each new venture revealed that the Lean Startup Approaches had a pervasive influence on the way of thinking and conducting the business since the very set up of the business, as clearly stated by Founder of Crowd:

"In the very beginning, I was too much in love with my business idea and my mind started to think to an enormous quantity of additional services and features to offer to my clients. Soon I realized that that way of thinking was overwhelming for me in that moment and that I was wasting my energy and resources in making everything more complicated than it was. Here, few but essential concepts of LSAs - like the MVP - really helped me out to both realize first, and then correct, my way of thinking while setting up the business. Indeed, I started to focus, focus and focus in providing and improving only those services that were central in our mission rather than wasting time in thinking to additional and "nice to have" services.

Founder of Crowd offered also an interesting addition by revealing the influence of his previous job experience: 
"I had been working in Operations for a multinational company that was pretty much loyal to the lean manufacturing principles. As a result, I believe customer centricity and focus on key business aspects always guided my way of thinking, which is something I recognize in both lean approaches: LSAs and LM".

This evidence offered an interesting insight on the importance of the Lean Thinking - as common ground on which both LM and LSA are based. Thus, what inductively emerged from the interview is that the connection between the two approaches appears clear also to practitioners.

More importantly, the interviews revealed that the business model change process has been influenced by the LSAs.

"Since the beginning of my adventure with Crowd, I felt the need to be in a close relationship with my customers; in certain phases I let them guide and suggest the changes they would be happy to find while experiencing the full purchase. For instance, the process of job self-creation was too complex for client-companies and no indicator was giving us this info, we had to go and talk to clients." (Founder of Crowd).

Thus, we argue that following the "get out of the building" LSAs' principle facilitated the identification of a strategic change needed in the way they were conducting their business (which eventually resulted in a full BM). Similarly, Founder of Matching stated that following the principle of "build measure and learn" they realized the company needed a change in the revenue model.

In addition to the identification of a strategic change needed, also the processing and execution of such a change was guided by Lean Startup Approaches' fundamental concepts and principles. To this regard, here Founder of Navigate explains:

"Explore and set up a new business model while the old one is still performing well is quite a challenge. Specifically, your limited resources - basically time and money - become even more scarce, thus, any waste is a great lost with potential great consequence. We really had to be very focused on core services needed to provide and improving fast by providing only what customer seem to like".

This evidence, though implicitly, underlines how concepts such as experimenting and validation, MVP and Customer feedback (over intuition and heuristics) play a fundamental role in orienting also the execution phase of Business Model Change. Concerning this point, case (Navigate) is of a particular interest, since it is a case of "playing both games at once", thus exploring and exploiting business model change in accordance with Osiyevskyy and Dewald (2015) BMC's conceptualization. 
Moreover, the continuous customers' feedback process emerges as a core resource while in needed to perform business model changes, in accordance to the customer development theory (Blank, 2006). Indeed, Founder of Crowd stated that "the re-engineering of the self-job creation process was merely the result of a continuous customers' feedbacks process". Figure 2, while illustrating an example of how data were structured in this study (as described in Section 3.2), shows some key overarching dimensions. These dimensions represent a synthesis of the role of Lean Startup Approaches in Business Model Change Process.

Figure 2. Data Structure and Lean Business Model Change

1st Order Concepts 2nd Order Themes

LSA to identify the strategic

change needed

\section{Model}

Overarching Dimensions

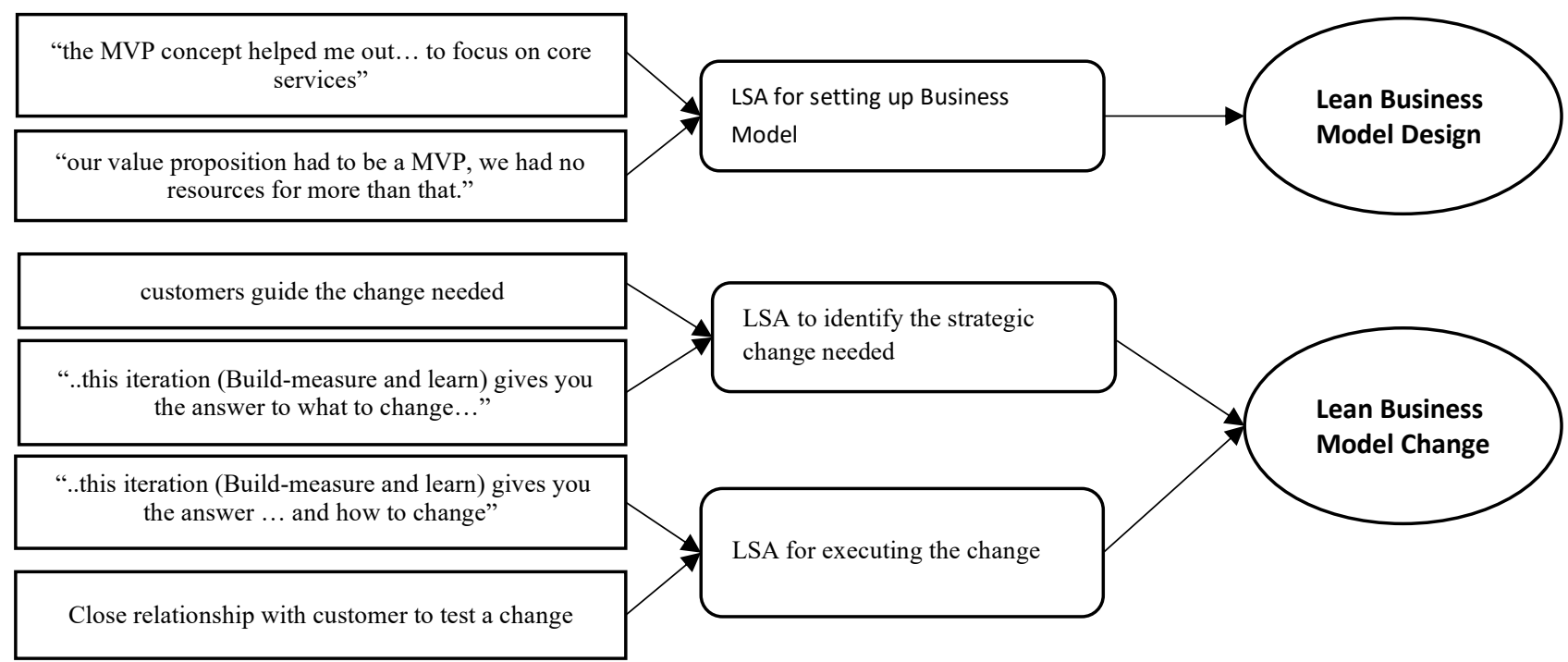

“..this iteration (Build-measure and learn) gives you the answer to what to change..."

It is noteworthy to specify that Figure 2 is not meant to be an exhaustive illustration of the first order concepts collected during the interviews, neither a causal nor a dynamic model but, rather, is a selective representation of the core concepts and their relationships.

\subsection{Business Model Change as a Lean Process}

Beyond the finding that relates BMC and LSAs in new ventures, the case study revealed a multiphase "common pattern" followed by all new ventures while facing a business model change process. Figure 3 shows this common pattern, described as follows.

The first step (phase 0 in Figure 3 ) includes identifying the strategic change needed. For instance, Crowd found as strategic area of improvement a key activity: the "job self-creation function" - which was making 
unsatisfied the customers, thus reducing also the chance to get new ones; Crowd, by looking at metrics, found revenues low while other all other metrics were growing significantly, thus revealing the need to rethink the revenue model and cost structure; finally, Navigate demonstrates that also when you do not see any evident negative signal on the current way you are conducting your business, a change may be required. During the interviews the founder of Navigate reinforced this idea many times: "At that time, we didn't need or see any need of change. It was during a meeting with my team, while we were discussing of getting external funding to finance our growth, that I asked to myself and my team if we were getting the most from our asset and resources first. In the end, we realized that we were able to collect a lot of data that we were basically not using at all. That was a key moment for our company".

After identifying the strategic change needed, new ventures should start to "prepare the company" (phase 1 in Figure 3) to the change before processing it (e.g. acquire new knowledge, hire new resources, create new partnerships or activities to deliver value). As regard, Crowd introduced a new sales function, while rethinking the job creation activity; Matching gradually started to dismiss all the expensive operations connected to the "debt collection" activity, preparing the company to shift to a new revenue model; and $\mathrm{N}$ started to partnering with beacon producers and in parallel acquiring new knowledge on digital advertising. According to the entrepreneurs, phase 1 allows enhancing efficiency and scalability while reducing the time of transition during the business model change from the client perspective, due to the provided internal consistency. This laid the foundations for phase 2 (Figure 3): "prepare the customer and testing". For instance, you may need to change the relation with your customers and test it on a sample and this is the case of Crowd where a self-automated (online) relationship was substituted with a direct contact and customized service. Similarly, Founder of Matching, during the interviews reinforced this idea: "we couldn't switch immediately to the new revenue model, which is a kind of shock for customers that can seriously undermine your customer base. We needed to test on a small portion of our customers and prepare them, make it easy, and I would say also convenient. Customers need to feel happy and safe. We communicated the change in a way that our customers knew we had everything under control"; (in Appendix B, we provide the communication sent by Matching to prepare their customers to the change). Also, Navigate tested first the new app (an MVP with basic features) only Google Play store - a way of sampling the customer base since their main channel was the Apple store.

Only once the testing phase (phase 2 ) returns positive results, the business model change process can be completed and fully executed. Hence, when both the company and the customer are ready, it is finally possible execute the business model change (phase 3 in Figure 3 ) including for instance communicating the changed value proposition or revenue model to the customer base in order to capture the value created from the changes. Indeed, Navigate fully developed the app and extended also a new version for available to Apple store, B extended the new way of performing the job creation activity to all the customer base; Matching introduced and communicated to all the customer base the change in revenue model and related 
activities. Finally, in case of negative response from the testing phase, all the previous phases $(0 ; 1 ; 2)$ should be reconsidered and changed accordingly.

Figure 3. Business Model Change Process

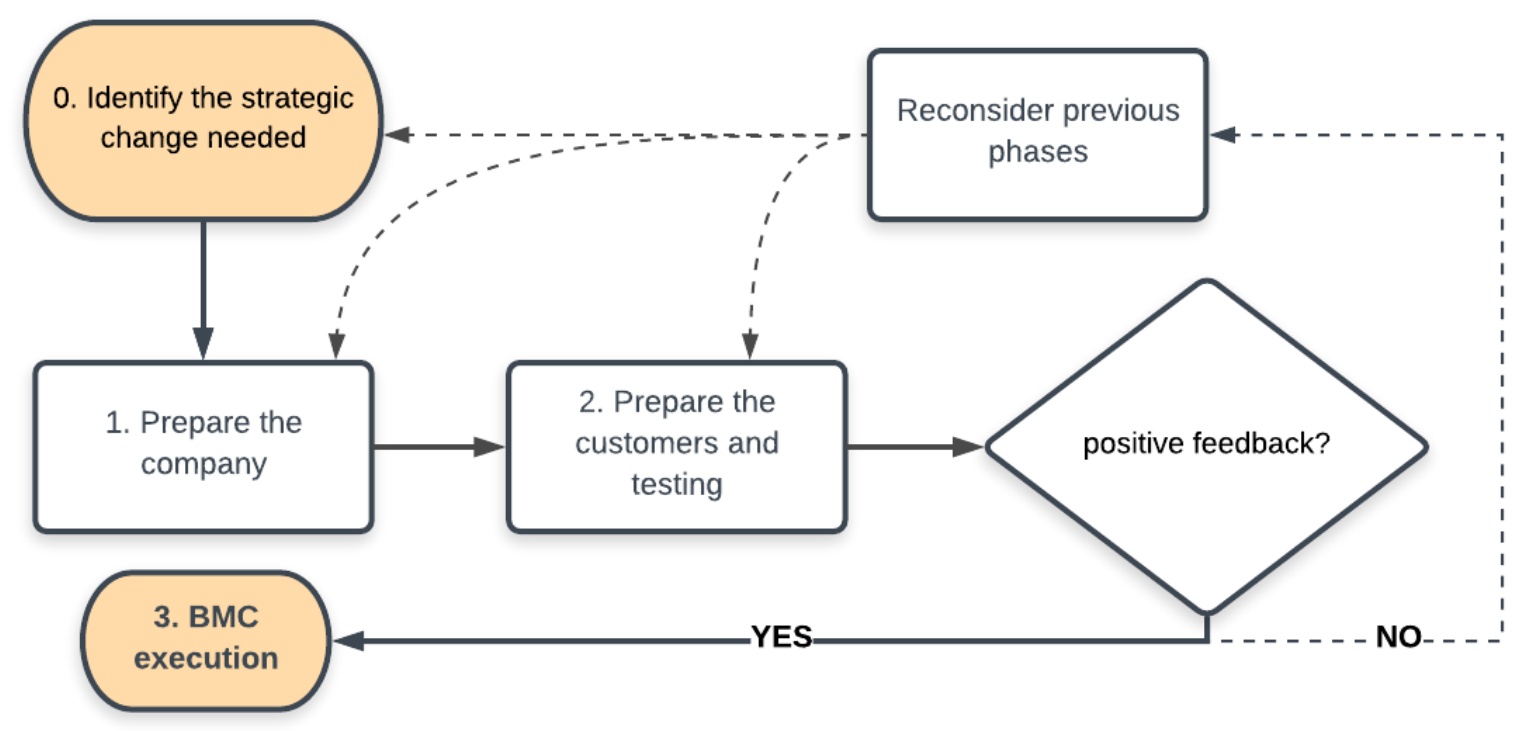

These findings imply the existence of internal consistency in the decisions made by the entrepreneurs before modifying what is offered to the customer. The concept is coherent with the LSAs vision, according to which "customers are always first". Indeed, like the Matching and the Crowd cases suggest, proper communication or even a Wizard of $\mathrm{Oz}$ testing can be beneficial before the introduction of the new business model.

However, the multiple case study also suggests an extension to the LSAs as traditionally conceived and practiced. Even though customers are still a fundamental part of the transformation, as a first step, new ventures need to prepare the company to deliver value coherently to the new business model hypotheses. For instance, Navigate acquired new partners, resources, competences and developed a new unique application before launching a test in the Google Play store.

Communication with customers is an essential phase that can creates loops back to a new modification of the internal value infrastructure (resources, activities, partnerships). However, it is important that these modifications occur in the testing phase, before the launch of the new business model for keeping the process lean. Moreover, based on Osiyevskyy and Dewald's BMC conceptualization (2015), it is noteworthy to highlight that this common pattern has been followed by new ventures performing exploitation business model change - incremental changes on their current business model such as case Crowd and Matching - as well as exploration of a new business model (while keeping the existing one) as for the case Navigate. 


\subsection{A framework extending LSAs: SMED for Business Model Change}

Making one step forward LSAs conceptualization and operationalization, consistently with the study's objectives, the common pattern for BM changes identified through the case studies has been formalized in an integrated framework that may guide entrepreneurs while processing a lean business model change.

Starting from the recognition that LSAs' roots in Lean Thinking could lead to an extension of these entrepreneurial approaches, we developed this framework by leveraging the analogies we fund with a notorious tool of the Lean Manufacturing: SMED (Single Minute Exchange of Die). SMED is a method developed in the Toyota Production System enabling "the execution of setup change processes in less than ten minutes" (Dillon and Shingo, 1985). SMED has received a widespread consensus by both scholars and practitioners as tool enabling a change process with strategic impact on several companies especially during the 80 s and 90s (Dillon and Shingo, 1985, Hall, 1983, McIntosh et al., 2007). The possibility of having a faster change process leads to higher flexibility and responsiveness of the organization to the customer demand (Moxham and Greatbanks, 2001).

SMED captured our attention based on a twofold reason. First, it is a practical tool specifically supporting a change process - that is, the set-up change process in production. The possibility of having a faster change process leads to higher flexibility and responsiveness of the organization to the customer demand (Moxham and Greatbanks, 2001). Second, it is inspired by the Lean thinking. In parallel, the case studies revealed a common pattern followed by the new ventures while processing a change process (BMC) and explicitly inspired and influenced by the Lean Thinking. Thus, by comparing SMED and the BMC process followed by new ventures, several analogies emerged that need to be discussed (see Figure 3 for BMC process and see Appendix A - Figure 5 for SMED).

SMED starts by identifying operations that need to be executed to change the set-up; in turn, BMC process start by identifying the strategic change needed to be executed to perform a BMC. In the following two phases, both SMED and BMC processes group and prioritize the changes that are more promising (i.e., the ones with the best cost/benefit ratio) or that precede bigger changes. Specifically, in SMED, external operations are performed first, while in BMC process, new ventures first prepare the company to create and capture the value in a new way. Differently from internal operations, external operations are those operations that do not require a stop in production. Similarly, experimenting changes in BM such as changes in activities to deliver value and/or test a new economic formula with a sample of customers are changes that customers do not perceive, and can be introduced even while keeping the current BM running. In SMED, once the external operations are completed, internal operations are performed and the set-up change can be executed. In a similar vein, when the tests return positive feedback by the customers' sample, the BMC process can be finally executed. 
There are however some differences between BMC process and set-up change process. For instance, while executing a BMC process may produce a Multiple Business Model configuration (introducing a new BM while keeping running the old one - as in the case of Navigate), this cannot happen in the SMED context (since the company cannot have multiple set-ups running at once unless operating different machines). Another key difference is that SMED has an eye towards simplifying or changing elements so that the task can be completed in less time. In BMC, the main purpose is not that much to reduce time but to make sure that changes are meaningful for the customer and are efficiently implemented.

In addition to the considerations above, we posit that the basic concept behind the SMED methodology that acts as a connector to the BMC process is that not all the operations are the same. Said differently, activities are of different nature, and following a coherent order not only matters but is what really makes the difference (Dillon and Shingo, 1985). This concept holds also true for the change process regarding business models as shown in the examples reviewed. Thus, by revisiting the Lean Manufacturing tool of SMED, we introduce an integrated framework that may guide entrepreneurs while processing a lean business model change: SMED4BMC (Figure 4).

Figure 4 - An integrated framework for BM change process in digital new ventures: SMED4BMC

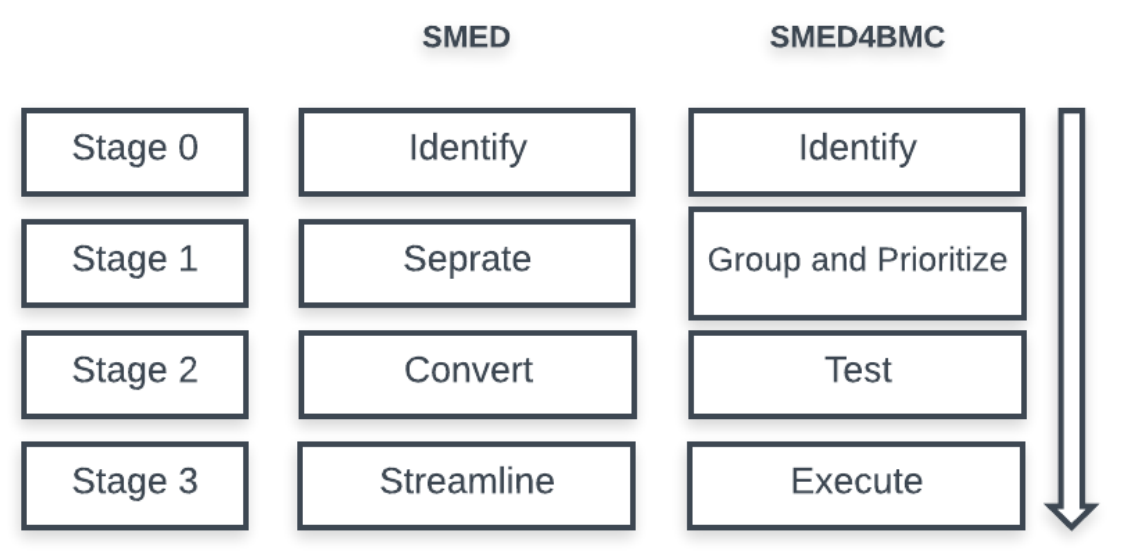

The integrated framework presented, called SMED for Business Model Change (SMED4BMC), while providing guidelines for executing and manage business model change, enters in the LSAs framework and extends its scope since it can be used in every process of business model change and not just in initial pivotal in early stages. The SMED4BMC particularly fits digital new ventures that operate in a very dynamic context where changes are needed not only in the very early stages of startup. Change can even become a permanent state (Demil and Lecocq, 2010), and this could be very likely true in the case of digital new ventures. However, long 
periods of co-existence of current and new model and organizational problems can arise (Chesbrough, 2010). This multiple business models (MBMs) configuration is often seen as a risk that needs to be managed (Massa and Tucci, 2013). Nevertheless, the empirical evidence in the Navigate case suggests that there are situations in which MBMs are identified and pursued as an exploration opportunity. While a MBM configuration may not be sustainable as startups scale and consolidate (Doz and Kosonen, 2010; Massa and Tucci, 2013), startups often inherently look for a MBM condition to experiment and scan for opportunities. Therefore, the coexistence of more than one business model, rather than a mere risk, may be perceived by entrepreneurs as a sort of "strategic fuzziness" startups seek for to remain flexible. Nonetheless, MBM strategic orchestration in a new venture needs to be supported by strategic tools enabling to seek and exploit opportunities while countering risks of misalignment, inconsistency, unclear direction and resources waste. The SMED4BMC represents a possible step that goes in this relevant direction. Obviously, here as elsewhere one size does not fit all, and there should be no hesitation whatsoever to deviate from our proposed steps in SMED4BMC as long as such variation is well motivated.

\section{Conclusion}

This study starts from the fundamental assumption that the Lean thinking-already shifted from the manufacturing area and applied into the entrepreneurial strategy world through an early approach (the Lean Startup Approaches) - may play a significant role in advancing the business model research in its theory and operative tools. Indeed, the "lean" perspective offers principles and methods able to improve the execution of processes, from a single, small task to the overall organizational configuration.

Rooted in this context, this study has explored how LSAs can help in BMC process. The study builds its contribution on two main pillars: a review on BM and the lean thinking theories, and a multiple case study on three digital new ventures which underwent BMC. The initial assumption that the BMC can beneficially follow the lean principles is formalized by presenting an integrated framework (SMED4BMC) as result of a multiphase "common pattern" informed by case studies and formalized adapting the lean manufacturing tools (SMED-ZERO and SMED). As result, the study contributes to the both the lean thinking and the BM theories and practices by: (i) enhancing the theoretical foundations of LSAs, which combine ideas borrowed from agile development and customer development with the concept of lean development and innovation; and (ii) establishing an explicit relationship between the lean thinking and business model experimenting, validation and innovation (with specific reference to Digital contexts). In line with this, our study contributes to the research on how to make the BM a unit of analysis for an experimenting process (e.g. Morris et al., 2005; Doz and Kosonen, 2010; Teece, 2010), this time under severe constraints to creativity and innovation (Acar et al., 2018) determined by new ventures' resource scarcity; the final objective being to scientifically obtain business model validation (Ghezzi, 2018) and enable change. 
Research value is also connected to the BM literature. We advance the current knowledge by proposing a framework for Business Model Changes process which may serve for future studies both qualitative and quantitative.

This study may also lead to some practical implication. We argue that the SMED4BMC framework supports and smooths every business model change to customers' eyes. At the same time, the framework enters in the LSAs and goes beyond its scope since it can be used in every process of business model change and not just in initial pivotal in early stages. Given the high uncertainty intrinsic to entrepreneurship, this framework should not be understood as a method for standardizing BM changes, but as a set of guidelines along the process entrepreneurs may use and adapt to their business case. In this respect, this study also reinforces the claim that business models should be assessed as complex and dynamic elements (Massa and Tucci, 2013). Certainly, the SMED4BMC framework is particularly suitable for companies operating in dynamics sectors-such as the digital one, already covered in this study-in which companies operate in a highly volatile setting where flexibility and adaptation are paramount throughout all firms' life cycle. We therefore argue that entrepreneurs when building their company should adopt of a dynamic perspective as mandatory strategic approach in the current constantly changing business environment. Setting up a process of continuous change, adaptation and innovation will be more and more often the core of the business planning process (Mitchell and Coles, 2003). However, this is not an easy task, and entrepreneurs are in need of tools and inspiring principles such as the one presented here that may guide their actions. This perspective may also lead to the exploration of different research methodologies such as "system thinking" (Sterman, 2001) which should be further investigated in future studies. Moreover, not only entrepreneurs are involved in business model change process. Managers for both small and large incumbent companies have to deal with a dynamic environment that is triggering their proven and traditional business model. Thus, our framework can be considered while adapted to the specific context to also incumbent companies.

Overall, we conclude that advancing the understanding of Business Model Change is a relevant and urgent topic. The digital revolution, intended as the transformation brought in by pervasive and multipurpose digital technologies (Bharadwaj et al., 2013), is influencing entire industries, e.g. healthcare (Steinhubl et al., 2013), education (Hiltz and Turoff, 2005) and public sector (XU et al., 2002) in terms of reshaping or even destroying entire sectors while creating new ones (Downes and Nunes, 2014). New digital ventures are often leading this revolution; however, the low level of entry barriers and market dynamicity makes it difficult for newcomers themselves to survive and consolidate. The "competitive war" in the new market scenario hence involves new ventures as well as larger organizations, and while new ventures may benefit from their inherent flexibility, they also have to cope with strong financial and resource constraints limiting their course of action. 


\section{Limitations and future research}

Further research can mend this study's limitations-related to the limited size and industry specificity of the theoretical sample and the observer bias characterizing qualitative methodologies-by validating and customizing the model in contexts different than the digital one where this research had its focus. For instance, business models should be assessed as complex and dynamic elements, thus, a methodological approach as the system thinking (see Sterman, 2001) may inform future studies and contributing to advance the current understanding of BM.

Although the SMED4BMC has been designed for supporting entrepreneurs in flexible organizations, its application in more structured companies deserves further attention, thus, highlighting the possibility to further explore the role of the lean thinking to develop business strategy.

Appendix A - Figure 5. SMED

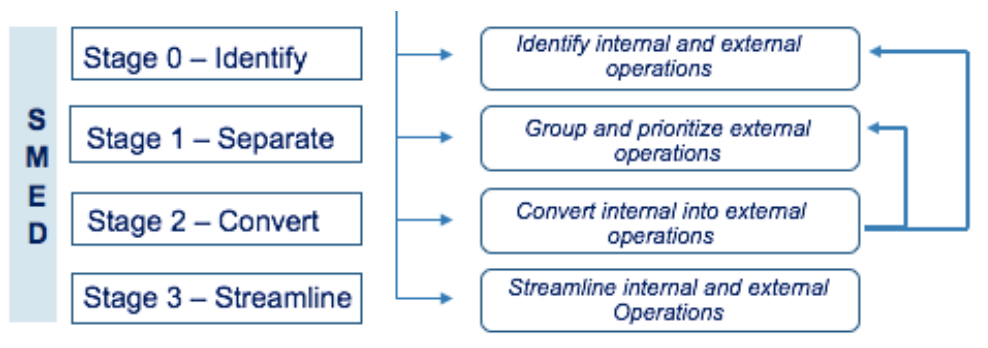

Appendix B. Preparing customers to the change (Case: Matching)

“Dear Professional XXXXX,

We are glad of your constant use of the service and we are always committed to guarantee you the best service.

By listening to your opinions and feedbacks during these months of collaboration, we know that:

Despite the strong attachment to our digital service, it is still clear to us your desire of getting in touch with the clients, preferably by telephone, from the very early stages, to make your quote proposal and commercial approach even more effective.

The lack of direct communication with the client causes the extend of the lead time, crucial parameter for your activities and for the whole company alike. 
After an accurate analysis ran by our team, with the support of some of your representatives interviewed (professionals partners), we came to the decision to offer you an alternative solution of use of the platform that we are confident it will be successful in your future.

Hereafter, we show you our new commercial offer and we also invite you to read at the following link our updated Terms \& Conditions, ready to be compiled for your acceptance (or your possible unsubscribe if you deem appropriate).

As always, we remain at your disposal for any kind of additional clarification at the Support email address:

$X X X X X$

Sincerely,

The Matching Team"

\section{References}

Acar, O. A., Tarakci, M., \& van Knippenberg, D. 2018. Creativity and Innovation Under Constraints: A Cross-Disciplinary Integrative Review. Journal of Management, 0149206318805832.

Achtenhagen, L., Melin, L. \& Naldi, L. 2013, "Dynamics of business models-strategizing, critical capabilities and activities for sustained value creation", Long range planning, vol. 46, no. 6, pp. 427442.

Afuah, A. \& Tucci, C.L. 2001, Internet business models and strategies, McGraw-Hill New York. 
Amit, R. \& Zott, C. 2012, "Creating value through business model innovation", MIT Sloan Management Review, vol. 53, no. 3, pp. 41-49.

Amit, R. \& Zott, C. 2001, "Value creation in e-business", Strategic Management Journal, vol. 22, no. 6-7, pp. 493-520.

Andries, P. \& Debackere, K. 2006, "Adaptation in new technology-based ventures: Insights at the company level", International Journal of Management Reviews, vol. 8, no. 2, pp. 91-112.

Bajwa, S.S., Wang, X., Duc, A.N. \& Abrahamsson, P. 2017, "'Failures" to be celebrated: an analysis of major pivots of software startups", Empirical Software Engineering, vol. 22, no. 5, pp. 2373-2408.

Baldassarre, B., Calabretta, G., Bocken, N. \& Jaskiewicz, T. 2017, "Bridging sustainable business model innovation and user-driven innovation: A process for sustainable value proposition design", Journal of Cleaner Production, vol. 147, pp. 175-186.

Bharadwaj, A., El Sawy, O., Pavlou, P. \& Venkatraman, N. 2013, "Digital business strategy: toward a next generation of insights", MIS Quarterly, vol. 37, no. 2, pp. 471-482.

Bicen, P. \& Johnson, W.H. 2015, "Radical Innovation with Limited Resources in High-Turbulent Markets: The Role of Lean Innovation Capability", Creativity and Innovation Management, vol. 24, no. 2, pp. 278-299.

Blank, S. 2006, "The Four Steps to the Epiphany Successful Strategies for Products that Win, lulu. com", .

Blank, S. 2013, "Why the lean start-up changes everything", Harvard business review, vol. 91, no. 5, pp. 63-72.

Bohnsack, R., Pinkse, J. \& Kolk, A. 2014, "Business models for sustainable technologies: Exploring business model evolution in the case of electric vehicles", Research Policy, vol. 43, no. 2, pp. 284300.

Bonoma, T.V. 1985, "Case research in marketing: opportunities, problems, and a process", Journal of Marketing Research, , pp. 199-208.

Brad, S., Murar, M. \& Brad, E. 2016, "Methodology for lean design of disruptive innovations", Procedia CIRP, vol. 50, pp. 153-159.

Calcagnini, G., Favaretto, I., Giombini, G., Perugini, F. \& Rombaldoni, R. 2016, "The role of universities in the location of innovative start-ups", The Journal of Technology Transfer, vol. 41, no. 4, pp. 670693.

Caldera, H., Desha, C. \& Dawes, L. 2017, "Exploring the role of lean thinking in sustainable business practice: A systematic literature review", Journal of Cleaner Production, vol. 167, pp. 1546-1565.

Cavallo, A., Ghezzi, A., \& Balocco, R. (2018a). Entrepreneurial ecosystem research: Present debates and future directions. International Entrepreneurship and Management Journal, 1-31.

Cavallo, A., Ghezzi, A., Colombelli, A., \& Casali, G. L. (2018b). Agglomeration dynamics of innovative start-ups in italy beyond the industrial district era. International Entrepreneurship and Management Journal, 1-24.

Charitou, C.D. \& Markides, C.C. 2003, "Responses to disruptive strategic innovation", MIT Sloan Management Review, vol. 44, no. 2, pp. 55-64.

Chesbrough, H. 2010, "Business model innovation: opportunities and barriers", Long range planning, vol. 43 , no. 2-3, pp. 354-363. 
Chesbrough, H. 2007, "Business model innovation: it's not just about technology anymore", Strategy \& leadership, vol. 35, no. 6, pp. 12-17.

Chesbrough, H. \& Rosenbloom, R.S. 2002, "The role of the business model in capturing value from innovation: evidence from Xerox Corporation's technology spin-off companies", Industrial and corporate change, vol. 11, no. 3, pp. 529-555.

Choudhary, P., Mital, M., Pani, A. K., Papa, A., \& Vicentini, F. (2018). Impact of enterprise mobile system implementation on organizational ambidexterity mediated through BPM customizability. Business Process Management Journal.

Christensen, C. 1997, "Patterns in the evolution of product competition", European Management Journal, vol. 15, no. 2, pp. 117-127.

Christensen, C.M. 2006, "The ongoing process of building a theory of disruption", Journal of Product Innovation Management, vol. 23, no. 1, pp. 39-55.

Colombelli, A. 2016, "The impact of local knowledge bases on the creation of innovative start-ups in Italy", Small Business Economics, vol. 47, no. 2, pp. 383-396.

Costa, Eric Simão Macieira da, Sousa, R.M., Bragança, S. \& Alves, A.C. 2013, "An industrial application of the SMED methodology and other Lean production tools", $4^{\text {th }}$ International Conference on Integrity, Reliability and Failure, Funchal/Madeira, 8, 23-27.

Courtney, H., Kirkland, J. \& Viguerie, P. 1997, "Strategy under uncertainty", Harvard business review, vol. 75 , no. 6, pp. 67-79.

Demil, B. \& Lecocq, X. 2010, "Business model evolution: in search of dynamic consistency", Long range planning, vol. 43, no. 2-3, pp. 227-246.

Denzin, N.K. 1978, "The research act: A theoretical orientation to sociological methods", McGraw-Hill.

Dezi, L., Pisano, P., Pironti, M., \& Papa, A. (2018). Unpacking open innovation neighborhoods: Le milieu of the lean smart city. Management Decision, 56(6), 1247-1270.

Dillon, A.P. \& Shingo, S. 1985, A revolution in manufacturing: the SMED system, CRC Press.

do Rosário Cabrita, M., Duarte, S., Carvalho, H. \& Cruz-Machado, V. 2016, "Integration of Lean, Agile, Resilient and Green Paradigms in a Business Model Perspective: Theoretical Foundations", IFACPapersOnLine, vol. 49, no. 12, pp. 1306-1311.

Downes, L. \& Nunes, P. 2014, Big bang disruption: Strategy in the age of devastating innovation, Penguin.

Doz, Y.L. \& Kosonen, M. 2010, "Embedding strategic agility: A leadership agenda for accelerating business model renewal", Long range planning, vol. 43, no. 2-3, pp. 370-382.

Eisenhardt, K.M. 1989, "Building theories from case study research", Academy of management review, vol. 14, no. 4, pp. 532-550.

Foss, N.J. \& Saebi, T. 2017, "Fifteen years of research on business model innovation: How far have we come, and where should we go?", Journal of Management, vol. 43, no. 1, pp. 200-227.

Frederiksen, D.L. \& Brem, A. 2017, "How do entrepreneurs think they create value? A scientific reflection of Eric Ries' Lean Startup approach", International Entrepreneurship and Management Journal, vol. 13 , no. 1 , pp. 169-189.

Gersick, C.J. 1994, "Pacing strategic change: The case of a new venture", Academy of management journal, vol. 37, no. 1, pp. 9-45. 
Ghezzi, A. 2018. "Digital Startups and the adoption and implementation of Lean Startup Approaches: Effectuation, Bricolage and Opportunity Creation in practice". Technological Forecasting and Social Change. DOI: https://doi.org/10.1016/j.techfore.2018.09.017

Ghezzi, A. \& Cavallo, A. 2018, "Agile Business Model Innovation in Digital Entrepreneurship: Lean Startup Approaches", Journal of Business Research, DOI: 10.1016/j.jbusres.2018.06.013.

Gioia, D.A., Corley, K.G. \& Hamilton, A.L. 2013, "Seeking qualitative rigor in inductive research: Notes on the Gioia methodology", Organizational Research Methods, vol. 16, no. 1, pp. 15-31.

Gioia, D.A., Price, K.N., Hamilton, A.L. \& Thomas, J.B. 2010, "Forging an identity: An insider-outsider study of processes involved in the formation of organizational identity", Administrative Science Quarterly, vol. 55, no. 1, pp. 1-46.

Girgenti, A., Pacifici, B., Ciappi, A. \& Giorgetti, A. 2016, "An Axiomatic Design approach for customer satisfaction through a Lean Start-Up framework", Procedia CIRP, vol. 53, pp. 151-157.

Glaser, B. \& Strauss, A. 1967, "Grounded theory: The discovery of grounded theory", Sociology the journal of the British sociological association, vol. 12, pp. 27-49.

Greve, H.R. 1998, "Performance, aspirations, and risky organizational change", Administrative Science Quarterly, , pp. 58-86.

Güemes-Castorena, D. \& Toro, M.A. 2015, "Methodology for the integration of Business Model Canvas and technological road map", 2015 Portland International Conference on Management of Engineering and Technology (PICMET), IEEE, pp. 41-52.

Hall, R.W. 1983, Zero inventories, Irwin Professional Pub.

Handfield, R.B. \& Melnyk, S.A. 1998, "The scientific theory-building process: a primer using the case of TQM", Journal of Operations Management, vol. 16, no. 4, pp. 321-339.

Hiltz, S.R. \& Turoff, M. 2005, "Education goes digital: The evolution of online learning and the revolution in higher education", Communications of the ACM, vol. 48, no. 10, pp. 59-64.

Hines, P., Holweg, M. \& Rich, N. 2004, "Learning to evolve: a review of contemporary lean thinking", International journal of operations \& production management, vol. 24, no. 10, pp. 994-1011.

Johnson, M., Christensen, C. \& Kagermann, H. 2008, "Reinvesting Your Business Model, w HBR's MustReads on Strategy, Harvard Business Review, vol. December, pp.59-68.

Kefalidou, G. \& Sharples, S. 2016, "Encouraging serendipity in research: Designing technologies to support connection-making", International Journal of Human-Computer Studies, vol. 89, pp. 1-23.

Kesting, P. \& Günzel-Jensen, F. 2015, "SMEs and new ventures need business model sophistication", Business horizons, vol. 58, no. 3, pp. 285-293.

Klewitz, J. \& Hansen, E.G. 2014, "Sustainability-oriented innovation of SMEs: a systematic review", Journal of Cleaner Production, vol. 65, pp. 57-75.

Knab, S. \& Rohrbeck, R. 2014, "Why intended business model innovation fails to deliver: insights from a longitudinal study in the German smart energy market", Proceedings of the R\&D Management Conference, Stuttgart, Germany.

Kulins, C., Leonardy, H. \& Weber, C. 2016, "A configurational approach in business model design", Journal of Business Research, vol. 69, no. 4, pp. 1437-1441.

Kurti, E. \& Haftor, D.M. 2014, "The Role of Path Dependence in the Business Model Adaptation: From Traditional to Digital Business Models", In: Mola, L., Carugati, A,. Kokkinaki, A., Pouloudi, N. (Eds.), 
Proceedings of the 8th Mediterranean Conference on Information Systems, Verona (Italy), September 3-5.

Lichtenstein, B.M.B. \& Brush, C.G. 2001, "How do "resource bundles" develop and change in new ventures? A dynamic model and longitudinal exploration", Entrepreneurship theory and practice, vol. 25, no. 3, pp. 37-58.

Magretta, J. 2002, "Why business models matter", Harvard Business Review, vol. 6.

Massa, L. \& Tucci, C.L. 2013, "Business model innovation", The Oxford handbook of innovation management, vol. 20, no. 18 , pp. 420-441.

Maurya, A. 2012, Running lean: iterate from plan A to a plan that works, O'Reilly Media, Inc.

McGrath, R.G. 2010, "Business models: A discovery driven approach", Long range planning, vol. 43, no. 2-3, pp. 247-261.

McIntosh, R., Owen, G., Culley, S. \& Mileham, T. 2007, "Changeover improvement: reinterpreting Shingo's "SMED" methodology", IEEE Transactions on Engineering Management, vol. 54, no. 1, pp. 98-111.

Meredith, J. 1998, "Building operations management theory through case and field research", Journal of Operations Management, vol. 16, no. 4, pp. 441-454.

Mitchell, D.W. \& Bruckner Coles, C. 2004, "Establishing a continuing business model innovation process", Journal of business strategy, vol. 25, no. 3, pp. 39-49.

Mitchell, D. \& Coles, C. 2003, "The ultimate competitive advantage of continuing business model innovation", Journal of Business Strategy, vol. 24, no. 5, pp. 15-21.

Morris, M., Schindehutte, M. \& Allen, J. 2005, "The entrepreneur's business model: toward a unified perspective", Journal of business research, vol. 58, no. 6, pp. 726-735.

Moxham, C. \& Greatbanks, R. 2001, "Prerequisites for the implementation of the SMED methodology: A study in a textile processing environment", International Journal of Quality \& Reliability Management, vol. 18, no. 4, pp. 404-414.

Mullins, J.W., Mullins, J.W., Mullins, J. \& Komisar, R. 2009, Getting to plan B: Breaking through to a better business model, Harvard Business Press.

Nicholls-Nixon, C.L., Cooper, A.C. \& Woo, C.Y. 2000, "Strategic experimentation: Understanding change and performance in new ventures", Journal of business venturing, vol. 15, no. 5-6, pp. 493-521.

Osiyevskyy, O. \& Dewald, J. 2015, "Explorative versus exploitative business model change: the cognitive antecedents of firm-level responses to disruptive innovation", Strategic Entrepreneurship Journal, vol. 9, no. 1 , pp. 58-78.

Osterwalder, A. 2004, The business model ontology: A proposition in a design science approach, $\mathrm{PhD}$ dissertation, Université de Lausanne École Des Hautes Etudes Commerciales.

Osterwalder, A. \& Pigneur, Y. 2010, Business model generation: a handbook for visionaries, game changers, and challengers, John Wiley \& Sons.

Osterwalder, A., Pigneur, Y. \& Tucci, C.L. 2005, "Clarifying business models: Origins, present, and future of the concept", Communications of the association for Information Systems, vol. 16, no. 1, pp. 1.

Pratt, M.G. 2008, "Fitting oval pegs into round holes: Tensions in evaluating and publishing qualitative research in top-tier North American journals", Organizational Research Methods, vol. 11, no. 3, pp. 481-509. 
Puri, M. \& Zarutskie, R. 2012, "On the life cycle dynamics of venture-capital-and non-venture-capitalfinanced firms", The Journal of Finance, vol. 67, no. 6, pp. 2247-2293.

Rappa, M. 2001, Managing the digital enterprise-Business models on the Web, http://digitalenterprise.org/models/models.html (retrieved 17 July 2018).

Reinertsen, D. \& Shaeffer, L. 2005, "Making R\&d Lean", Research-Technology Management, vol. 48, no. 4, pp. 51-57.

Ries, E. 2011, The lean startup: How today's entrepreneurs use continuous innovation to create radically successful businesses, Crown Books.

Rytkönen, E. \& Nenonen, S. 2014, "The Business Model Canvas in university campus management", Intelligent Buildings International, vol. 6, no. 3, pp. 138-154.

Saebi, T., Lien, L. \& Foss, N.J. 2017, "What drives business model adaptation? The impact of opportunities, threats and strategic orientation", Long range planning, vol. 50, no. 5, pp. 567-581.

Scherer, F.M. 1986, Innovation and growth: Schumpeterian perspectives, MIT Press Books, vol. 1.

Scuotto, V., Santoro, G., Bresciani, S., \& Del Giudice, M. (2017). Shifting intra-and inter-organizational innovation processes towards digital business: An empirical analysis of SMEs. Creativity and Innovation Management, 26(3), 247-255.

Sirmon, D.G., Hitt, M.A. \& Ireland, R.D. 2007, "Managing firm resources in dynamic environments to create value: Looking inside the black box", Academy of management review, vol. 32, no. 1, pp. 273-292.

Sosna, M., Trevinyo-Rodríguez, R.N. \& Velamuri, S.R. 2010, "Business model innovation through trialand-error learning: The Naturhouse case", Long range planning, vol. 43, no. 2-3, pp. 383-407.

Spieth, P., Schneckenberg, D. \& Ricart, J.E. 2014, "Business model innovation-state of the art and future challenges for the field", R\&d Management, vol. 44, no. 3, pp. 237-247.

Stam, E. (2015). "Entrepreneurial ecosystems and regional policy: a sympathetic critique". European Planning Studies, 23(9), 1759-1769.

Steinhubl, S.R., Muse, E.D. \& Topol, E.J. 2013, "Can mobile health technologies transform health care?", Jama, vol. 310, no. 22, pp. 2395-2396.

Sterman, J.D. 2001, "System dynamics modeling: tools for learning in a complex world", California management review, vol. 43, no. 4, pp. 8-25.

Still, K. 2017, "Accelerating Research Innovation by Adopting the Lean Startup Paradigm", Technology Innovation Management Review, vol. 7, no. 5.

Strauss, A. \& Corbin, J.M. 1990, Basics of qualitative research: Grounded theory procedures and techniques. Sage Publications, Inc.

Tanev, S., Rasmussen, E.S., Zijdemans, E., Lemminger, R. \& Svendsen, L.L. 2015, "Lean and global technology start-ups: linking the two research streams", International Journal of Innovation Management, vol. 19, no. 03, pp. 1540008.

Teece, D.J. 2010, "Business models, business strategy and innovation", Long range planning, vol. 43, no. 2-3, pp. 172-194.

Timmers, P. 1998, "Business models for electronic markets", Electronic markets, vol. 8, no. 2, pp. 3-8. 
Tracy, S.J. 2010, "Qualitative quality: Eight "big-tent" criteria for excellent qualitative research", Qualitative inquiry, vol. 16, no. 10, pp. 837-851.

Weissbrod, I. \& Bocken, N.M. 2017, "Developing sustainable business experimentation capability-a case study", Journal of Cleaner Production, vol. 142, pp. 2663-2676.

Wiese, A., Luke, R., Heyns, G.J. \& Pisa, N.M. 2015, "The integration of lean, green and best practice business principles", Journal of Transport and Supply Chain Management, vol. 9, no. 1, pp. 1-10.

Womack, J.P. \& Jones, D.T. 1996, "Lean thinking: Banish waste and create wealth in your organisation", Simon and Shuster, New York, NY, vol. 397.

Xu, H., Yang, L. \& Fang, Z. 2002, "Studies on supporting technology systems of digital urban planning", Journal of Wuhan University of Hydraulic and Electric Engineering, vol. 35, no. 7.

Yang, X., Sun, S.L. \& Zhao, X. 2018, "Search and execution: examining the entrepreneurial cognitions behind the lean startup model", Small Business Economics, , pp. 1-13. DOI: 10.1007/s11187-0179978-z.

Yin, R. 1984, Case study research, Sage.

Yin, R.K. 2013, "Validity and generalization in future case study evaluations", Evaluation, vol. 19, no. 3, pp. 321-332.

Yin, R.K. 2003, "Case study research design and methods", $3^{\text {rd }}$ edition, Applied social research methods series, vol. 5, Sage Publications

Zott, C. \& Amit, R. 2007, "Business model design and the performance of entrepreneurial firms", Organization science, vol. 18, no. 2, pp. 181-199.

Zott, C., Amit, R. \& Massa, L. 2011, "The business model: recent developments and future research", Journal of management, vol. 37, no. 4, pp. 1019-1042. 